\title{
Mechanosensitive gating of CFTR
}

\section{Wei Kevin Zhang, Dong Wang, Yuanyuan Duan, Michael M.T. Loy, Hsiao Chang Chan and Pingbo Huang}

Nat. Cell Biol. 12, 507-512 (2010); published online 18 April 2010; corrected after print, 9 July 2010

In the version of this letter initially published online and in print, Fig. $4 \mathrm{e}-\mathrm{j}$ were incorrectly labelled: $\mathrm{I}_{\mathrm{SC}}$ and $\Delta \mathrm{I}_{\mathrm{SC}}$ should be $\mathrm{I}_{\mathrm{CI}}$ and $\Delta \mathrm{I}_{\mathrm{CI}}$, respectively. The correct labelling is shown below. These errors have been corrected in both the HTML and PDF versions of the letter.
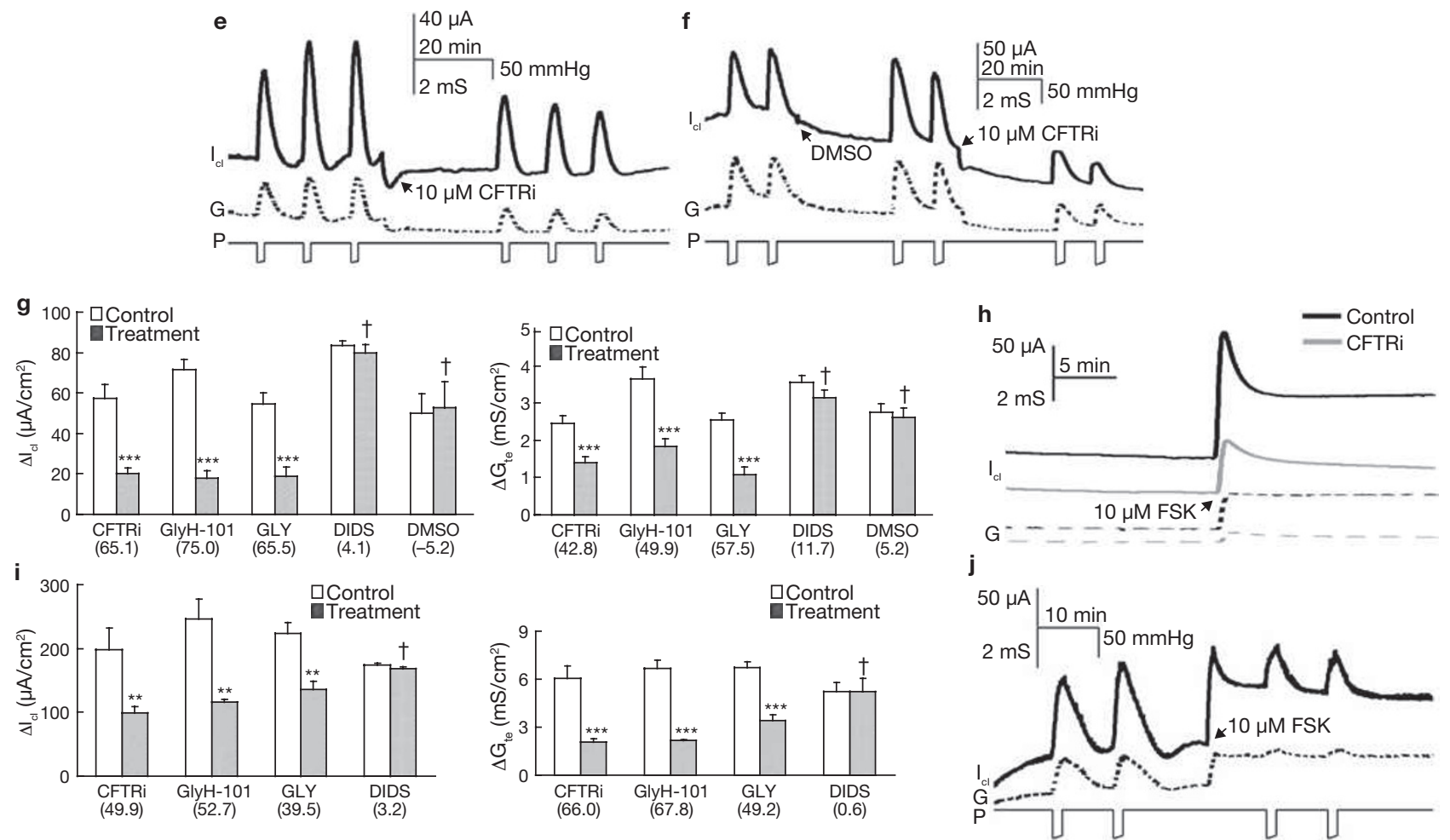